to have efficacy and safety similar to their reference products, were introduced to the UK market in February 2015 for rheumatoid arthritis (RA). Most research on RA biosimilars has been done in the context of clinical trials, but real world data are lacking. No national mandate exists in the UK to switch all patients from originator to biosimilars, but there are regional variations.

Objectives: This analysis aims to describe the characteristics of the first UK patients starting RA biosimilars registered with the British Society for Rheumatology Biologics Register for RA (BSRBR-RA).

Methods: Since 03/08/2015, the BSRBR-RA has captured data on patients starting biosimilars available in the UK: infliximab (Inflectra and Remsima) and etanercept (Benepali). At biosimilar start, information is captured from the hospital including demographic and clinical data, previous biologic exposure and if switching therapies, the reason for switch (as a tick box and free text). Follow-up data, including disease activity, occurrence of adverse events and changes to treatment is captured 6-monthly for 3 years and annually thereafter. Descriptive data are presented

Results: To 15/12/2016, 417 RA patients were recruited to the BSRBR-RA at point of starting a biosimilar for whom data were available for analysis on 414 participants: 47 (11\%) Inflectra, 78 (19\%) Remsima and 289 (70\%) Benepali. Of these, 138 started a biosimilar as first biologic, 242 switched directly from the originator product and 34 switched from an alternative biologic (Table). Patients switching from the originator did so after a median (IQR) of 6.7 (3.0-9.5) years and the majority had low disease activity (median DAS28 2.7 (IQR 2.0-3.9)). The switch reason was reported in $33 \%$ of patients, with cost listed as the main reason and "trust policy" included in $63 \%$ of 30 free text comments. Six-month follow-up data were available in 41 patients. Three patients on Remsima and 1 patient on Inflectra reported drug hypersensitivity reactions (rash, pruritus, hyperpigmentation), and $18 \%(6 / 34)$ of patients experienced a deterioration in their DAS28 of $>1.2$ after 6 months.

Table

\begin{tabular}{|c|c|c|c|}
\hline & Biological naive & $\begin{array}{l}\text { Switched from } \\
\text { reference product }\end{array}$ & $\begin{array}{l}\text { Not switched from } \\
\text { reference product }\end{array}$ \\
\hline Number & 138 & 242 & 34 \\
\hline \multicolumn{4}{|l|}{ Biosimilar, $n(\%)$} \\
\hline Inflectra & $3(2 \%)$ & $40(16 \%)$ & $4(12 \%)$ \\
\hline Remsima & $9(6.5 \%)$ & $65(27 \%)$ & $4(12 \%)$ \\
\hline Benepali & $126(91 \%)$ & $137(57 \%)$ & $26(76 \%)$ \\
\hline Women, $n(\%)$ & $108(78 \%)$ & $181(75 \%)$ & $28(82 \%)$ \\
\hline Age (years) & $\frac{506(780)}{56.0(48.064 .5)}$ & $\frac{101(17.0)}{67.0(57.0-72.0)}$ & $\frac{20(020)}{59.5(44.5-68.0)}$ \\
\hline Disease Duration (years) & $4.0(1.0-10.0)$ & $17.0(10.0-24.0)$ & $9.5(6.0-14.0)$ \\
\hline DAS28(CRP) & $5.9(5.3-6.5)$ & $2.7(2.0-3.9)$ & $5.1(3.5-6.2)$ \\
\hline \multicolumn{4}{|l|}{ Comorbidities } \\
\hline 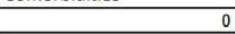 & $52(38 \%)$ & $84(35 \%)$ & $12(35 \%)$ \\
\hline 1 & $47(34 \%)$ & $84(35 \%)$ & $11(32 \%)$ \\
\hline 2 & $32(23 \%)$ & $32(13 \%)$ & $5(14 \%)$ \\
\hline $3+$ & $7(5 \%)$ & $42(17 \%)$ & $6(19 \%)$ \\
\hline \multicolumn{4}{|c|}{\begin{tabular}{|l|l|} 
Previous biological on $n(\%)$ \\
\end{tabular}} \\
\hline Enbrel & - & $137(57 \%)$ & $1(3 \%)$ \\
\hline Remicade & - & $105(43 \%)$ & $4(12 \%)$ \\
\hline Kineret & - & & $1(3 \%)$ \\
\hline Humira & - & - & $7(21 \%)$ \\
\hline Mabthera & - & - & $1(3 \%)$ \\
\hline Orencia & - & - & $4(12 \%)$ \\
\hline Simponi & . & - & $4(12 \%)$ \\
\hline RoActemra & - & - & $6(18 \%)$ \\
\hline Cimzia & - & - & $6(18 \%)$ \\
\hline \multicolumn{4}{|c|}{\begin{tabular}{|l|l|} 
Reasons to switch, $n(\%)$ & \\
\end{tabular}} \\
\hline Cost factors & $6(86 \%)$ & $107(86 \%)$ & $2(50 \%)$ \\
\hline Clinical indication & - & $5(4 \%)$ & $1(25 \%)$ \\
\hline Patient choice & - & $1(1 \%)$ & $1(50 \%)$ \\
\hline Other & $1(11 \%)$ & $11(9 \%)$ & \\
\hline Follow-up data available, $n$ & 5 & 35 & 1 \\
\hline DAS28 at 6 months & $3.9(3.1-7.1)$ & $2.8(2.2-3.9)$ & 5.3 \\
\hline
\end{tabular}

Conclusions: This preliminary study gives an early review of biosimilar use in the UK, showing that these drugs are used in patients with active disease as both first-line and subsequent-line biologics. Many patients with low disease activity are also being switched from originators primarily for cost reasons. Outcome data are limited but data capture will continue and updated reports from the BSRBR-RA will continue to be presented.

Disclosure of Interest: None declared

DOI: 10.1136/annrheumdis-2017-eular.3497

\section{FRI0197 ADHERENCE, SATISFACTION AND FULFILLMENT OF EXPECTATIONS OF PATIENTS WITH RHEUMATOID ARTHRITIS TREATED WITH SUBCUTANEOUS BIOLOGICALS. ARCO STUDY}

J. Calvo-Alén ${ }^{1}$, C. Marras ${ }^{2}$, I. Monteagudo ${ }^{3}$, G. Salvador ${ }^{4}$,

T. Vázquez-Rodríguez ${ }^{5}$, J. Tovar ${ }^{6}$, P. Vela ${ }^{7}$, F. Maceiras ${ }^{8}$, M. Bustabad $^{9}$,

E. Peiró ${ }^{10}$, J. Rosas ${ }^{11}$, M. Arteaga ${ }^{12}$, S. Fernández ${ }^{12}$, L. Cea-Calvo ${ }^{12}$,

Y. Mestre ${ }^{12}$, E. Raya ${ }^{13} \cdot{ }^{1} H$ Txagorritxu, Vitoria; ${ }^{2}$ HUV Arrixaca, Murcia; ${ }^{3} H G U$ Gregorio Marañón, Madrid; ${ }^{4} \mathrm{HU}$ Mútua Terrasa, Barcelona; ${ }^{5} \mathrm{HU}$ Lucus Augusti, Lugo: ${ }^{6} \mathrm{HGU}$, Elche $:{ }^{7} \mathrm{HGU}$. Alicante: ${ }^{8} \mathrm{CHU}$, Vigo: ${ }^{9} \mathrm{HU}$, Tenerife; ${ }^{10} \mathrm{HU}$ Marqués de Valdecilla, Santander: ${ }^{11} \mathrm{H}$ Marina Baixa, Alicante: ${ }^{12}$ Medical Affairs, Merck Sharp \& Dohme, Madrid; ${ }^{13} \mathrm{HU}$ San Cecilio, Granada, Spain

Background: In patients with rheumatoid arthritis (RA), we previously described that adherence to the subcutaneous (SC) biological treatment is better with monthly administration.

Objectives: We further assessed if there are differences in patients expectations and satisfaction with efficacy and tolerance that could contribute to explain such finding.

Methods: ARCO was a retrospective study on RA patients who had been prescribed a SC biological 11-18 months prior to the study. Adherence was calculated with the medication possession ratio (MPR). Satisfaction and expectations were assessed with the Spanish validated Carbonell questionnaire [1]

Results: We included 364 patients (age 54.9 years [SD 12.5], 77.5\% women, median duration of RA 7.8 years, period studied for the SC biological 14.8 months). Non-adherence (MPR $\leq 80 \%$ ) was lower in patients with monthly $(6.4 \%)$ than with weekly $(17.4 \%, \mathrm{p}=0.034)$ or every 2 weeks administration $(14.4 \%$, $\mathrm{p}=0.102$ ). The $\%$ of satisfied patients (quite/very satisfied) was $86.2 \%$ for efficacy and $64.4 \%$ for side effects or tolerance. Non-adherence was similar in satisfied with efficacy and in neutral/unsatisfied patients $(14.7 \%$ vs. $8.3 \%, \mathrm{p}=0.399)$, or in patients satisfied/not satisfied with side effects ( $13.1 \%$ vs. $15.4 \%, p=0.504)$. The fulfillment of expectations is shown in the table. With regard to expectations on the effect, non-adherence was 15.5\% (higher than expected), $12.6 \%$ (as expected) and $10.7 \%$ (lower than expected) ( $p=0.677$ ), and with regard to discomfort/side effects, it was $15.6 \%$ (greater than expected), $18.5 \%$ (as expected) and $11.1 \%$ (lower than expected, or no side effect) $(\mathrm{p}=0.189)$. Fulfilment of expectation on efficacy was similar for the 3 dosing schemes, but the \% reporting lower than expected discomfort or no discomfort was greater with fewer SC injections (table). In particular, the \% reporting no discomfort/side effects with the administration were $17.8 \%$ (weekly), $29.3 \%$ (every 2 weeks), and $35.0 \%$ (monthly) $(p=0.013$ )

\begin{tabular}{lccccc}
\hline & $\begin{array}{c}\text { All } \\
\%\end{array}$ & $\begin{array}{c}\text { Weekly } \\
\%\end{array}$ & $\begin{array}{c}\text { Every 2 weeks } \\
\%\end{array}$ & $\begin{array}{c}\text { Monthly } \\
\%\end{array}$ & $\mathrm{p}$ \\
\hline Effect of the treatment & & & & & \\
$\quad$ Much/quite higher than expected & 59.9 & 59.2 & 57.2 & 66.7 & 0.573 \\
$\quad$ More or less as expected & 32.1 & 33.6 & 33.8 & 25.0 & \\
$\quad$ Quite/much lower than expected & 8.0 & 7.4 & 9.0 & 8.3 & \\
$\begin{array}{l}\text { Discomfort } \\
\quad \text { Much/quite higher than expected }\end{array}$ & 13.0 & 15.8 & 11.5 & 10.1 & 0.048 \\
$\quad \begin{array}{l}\text { More or less as expected } \\
\text { Quite/much lower than expected or }\end{array}$ & 34.4 & 38.2 & 35.3 & 23.3 & \\
$\quad$ there were no discomfort & 52.5 & 46.0 & 53.2 & 66.6 & \\
\hline
\end{tabular}

Conclusions: RA patients on SC biological therapy show high satisfaction and fulfillment of expectations on efficacy, although both aspects lower for tolerance. Dosing regimen with lower number of SC injections seems to be associated with better fulfillment of expectations of tolerance. This finding, added to the lower number of injections itself, might explain the better adherence observed with monthly administration.

References:

[1] Carbonell J, Badia X; Grupo Expresar. Development and validation of a satisfaction questionnaire in patients with rheumatoid arthritis. Reumatol Clin 2006:2:137-45.

Acknowledgements: Funded by MSD, Spain.

Disclosure of Interest: None declared

DOI: 10.1136/annrheumdis-2017-eular.3176

\section{FRI0198 USABILITY AND SAFETY OF SB5 (AN ADALIMUMAB BIOSIMILAR) PRE-FILLED SYRINGE AND PRE-FILLED PEN IN PATIENTS WITH RHEUMATOID ARTHRITIS}

J. Ghil ${ }^{1}$, J. Niebrzydowski ${ }^{2}$, A. Zielińska ${ }^{3}$, Y. Lee ${ }^{1} .{ }^{1}$ Samsung Bioepis Co., Ltd., Incheon, Korea, Republic Of; ${ }^{2}$ Medica Pro Familia Sp. z o.o. S.K.A., Gdynia;

${ }^{3}$ Medica pro Familia Sp z o.o. S.K.A, Warszawa, Poland

Background: SB5 is developed as a biosimilar of the reference adalimumab (ADL). Equivalence in pharmacokinetics (PK) and efficacy between SB5-pre-filled syringe (PFS) and ADL-PFS has been demonstrated in a phase I and phase III study. ${ }^{1,2}$ The PK equivalence between SB5-PFS and SB5-pre-filled pen (PFP) in healthy subjects has been reported previously. ${ }^{3}$

Objectives: To compare the usability and safety of SB5-PFS and SB5-PFP from a phase II study.

Methods: This was an open-label, single-arm study in patients with rheumatoid arthritis (RA). Patients with RA self-administered a total of 6 injections of $40 \mathrm{mg}$ SB5 every other week; the first two injections were through PFS and the following four injections were through PFP. The primary objective of this study was to demonstrate comparability between PFS (at week 2) and PFP (at week 6) in terms of injection site pain score. Patients completed a pain evaluation questionnaire using an 11-point numeric rating scale at two time points (immediately and 15-30 minutes post-injection) after the first four injections. Equivalence between PFS and PFP was concluded if the $97.5 \%$ confidence interval $(\mathrm{Cl})$ of the difference in the injection site pain score was contained within the equivalence margin of \pm 5 . Other usability (overall impression and patient preference) and safety endpoints were also measured. 